\title{
Valor del recuento de Eosinófilos en secreción nasal en el diagnóstico diferencial de los cuadros bronquiales obstructivos del niño.
}

\begin{abstract}
DRS. ARMANDO DIAZ C. *, MIREYA BRAVO L. **, ELIANA CERUTI D. * y CARLOS CASAR C * ALUMNAS DE TECNOLOGIA MEDICA. SRTAS.: M. SILVA, $Z$. LAMAS, N. MARINOV y G. MALLEA.
\end{abstract}

La dificultad en el diagnóstico diferencial entre el asma bronquial y otros sindromes obstructivos, tanto en el adulto como en el niño, es un problema frecuente y conocido. Desde un punto de vista clínico, a veces es imposible hacer la diferenciación lo que obliga a recurrir a diversos exámenes de laboratorio que permitan comprobar o no la presencia de alergia, requisito indispensable para formular el diagnóstico definitivo de asma bronquial $(1,2,3,4,5)$.

Uno de los elementos que es posible estudiar en el Laboratorio es la secreción nasal. Eyermann (6) en 1927 hizo notar que la eosinofilia de Ia secreción nasal era un hecho frecuente en pacientes hipersensibles. Murray y Anderson (7) demostraron que es posible diferenciar las rinitis alérgicas de las vasomotoras e infecciosas mediante una tinción especial para eosinófilos en secreción nasal: en las rinitis alérgicas se encuentra gran cantidad de eosinófilos, los que en cambio están ausentes o en escasa cantidad en los otros tipos de rinitis. Lecks y Kravis (8) investigaron la presencia de eosinófilos en la secreción nasal y faringea de 20 niños con enfermedad respiratoria alérgica: 17 de ellos presentaron notable eosinofilia en la secreción nasal.

En base a estos bechos y considerando que la base patogénica de las rinitis alérgicas y del asma bronquial es semejante, numerosos autores $(1,3$, 9) han propuesto usar el estudio de los eosinófilos en la secreción nasal como un método más para probar el carácter alérgico de un cuadro bronquial obstructivo.

En el presente trabajo se estudia la eosinofilia en secreción nasal usando la tinción de Hansel en

\footnotetext{
* Laboratorio Cardiorrespiratorio. Hospital Roberto dol Río. Depto. de Pediatría, Area Norte. U. de Chile.

* Laboratorio de Hematología. Hospital Roberto del Río. Depto. De Pediatra. Area Norte, U. de Chile.
}

tres grupos de niños: sanos, con asma bronquial comprobada y con bronquitis crónica. Se analizan los resultados y se discute la utilidad del método.

Materual Y MÉTodo. Se estudiaron 39 niños de 6 a 14 años de edad que se dividieron en tres grupos:

1. - 12 niños con sindrome bronquial obstructivo crónico, con pruebas cutáneas para alergia negativas y con prueba de sensibilidad bronquial a la acetil colina $(10)$ negativa, antecedentes que permiten clasificarlos como "bronquitis crónica".

2.- 12 niños con sindrome bronquial obstructivo reversible, con antecedentes alérgicos personales y familiares y con pruebas cutáneas para alergia positivas, lo que permite su clasificación como asma bronquial.

3. - 15 niños normales, sin sintomatología de tipo bronquial o respiratorio $\mathrm{y}$ sin antecedentes personales ni familiares de enfermedades de tipo alérgico.

En todos los niños se tomaron muestras de secreción nasal succionándolas por ambas ventanillas nasales mediante una perita de goma y extendiendo las muestras en un porta objetos. Los frotis se tiñeron según el método de Hansel (11) que se describe a continuación.

Los reactivos usados son:

- Eosina 1/200 (0,30 grs. de eosina en $60 \mathrm{ml}$. de alcohol metílico).

- Azul de metileno 1/100 (0,60 grs. de azul de metileno en $60 \mathrm{ml}$. de alcohol metílico).

- Agua destilada.

- Etanol al 95\%.

La eosina y el azul de metileno deben mantenerse en frascos ámbar y deben ser renovados 
cada dos meses. Los pasos a seguir son los siguientes:

1. El trotis se seca al aire.

2. Se cubre con eosina y se deja un minuto.

3. Se agrega igual volumen de agua destilada y se deja un minuto.

4. Se bota la eosina y el agua y luego se cubre con agua destilada hasta remover la tinción.

5. Se cubre el frotis con etanol y luego se bota.

6. Se cubre nuevamente con azul de metileno y se deja un minuto.

7. Se agrega igual volumen de agua destilada y se deja 2 minutos.

8. Se lava hasta remover la tinción.

9. Se agrega etanol y se seca al aire.

10. Se examina al microscopio con lente de inmersión.

Con esta tinción el mucus nasal aparece de aspecto homogéneo y de color azul, las bacterias se tiñen azules y se puede distinguir 3 tipos de células:

1. Células epiteliales nasales, con citoplasma azul pálido abundante y núcleo azul no lobulado.

2. Neutrófilos, que tienen núcleos azul lobulado v citoplasma rosado pálido $\mathrm{y}$,

3. Eosinófilos, que tienen núcleo lobulado azul y citoplasma con gránulos intensamente eosinótilos que permiten distinguirlos con facilidad.

Si los neutrófilos no se han teñido bien se debe repetir el método desde el punto No 7 . Si los neutrófilos o el mucus se han teñido de un azul demasiado intenso se coloca una solución que contenga una gota de ácido hidroclórico al $1 \%$ en
30 cc de agua destilada sobre el frotis y se repiten los pasos desde el punto No 8 adelante.

En la tabla 1 se ban esquematizado las características observadas en los frotis de secreción nasal de los tres grupos de niños estudiados. Puede observarse claramente que 10 de los 12 niños asmáticos tenían eosinofilias sobre $5 \%$, y que en 7 de ellos esta eosinofilia era muy importante, sobre $20 \%$. Solo 1 de los niños no tenía eosinófilos en la secreción nasal y uno tenía menos de $5 \%$. En cl grupo de 15 niños normales 12 no presentaban eosinófilos o presentaban hasta $0,5 \%$ (aproximadamente 1 eosinófilo por lámina) y los tres que presentaban eosinofilos los tenían en muy cscasa proporción, siempre de $5 \%$ o menos $(5 \%$, $3 \%, 2 \%)$. En el grupo con bronquitis crónica no alérgica 11 no tenían eosinófilos o tenían sólo hasta $1 \%$, y sólo uno tenía una eosinofilia importante de $9 \%$.

En resumen, como puede apreciarse en la figura 1, hay una evidente diferencia entre la gran magnitud de eosinofilia encontrada en los nin̄os asmáticos y la escasa presencia de eosinófilos en los niños sin alergia demostrada, con o sin sintomatología bronquial crónica.

Discusión. Los resultados obtenidos permiten demostrar que la búsqueda eosinófilos en la secreción nasal mediante la técnica de Harsel es un examen de fácil realización y que constituye una ayuda en la diferenciación de los cuadros respiratorios de naturaleza alérgica. Su utilidad en el diagnóstico diferencial de rinitis la demostraron Murray y Anderson (7), y las significativas dife-

TA B L A No 1

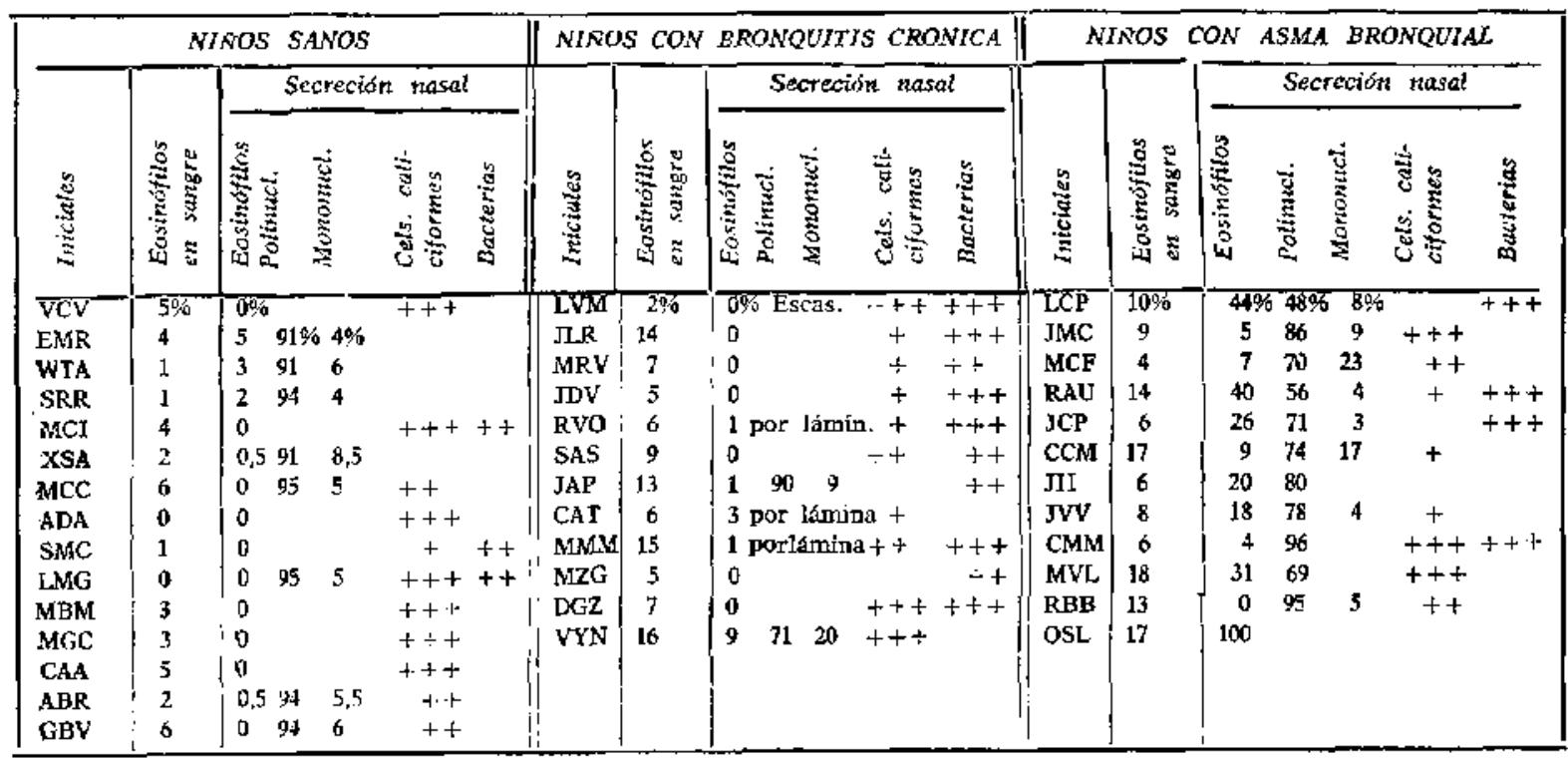

Caracteristicas del frotis nasal en niños sanos sin antecedentes alérgicos, en facientes con bronquitis crónica no alérgica y en enlermos con asma bronquial comprobada. 


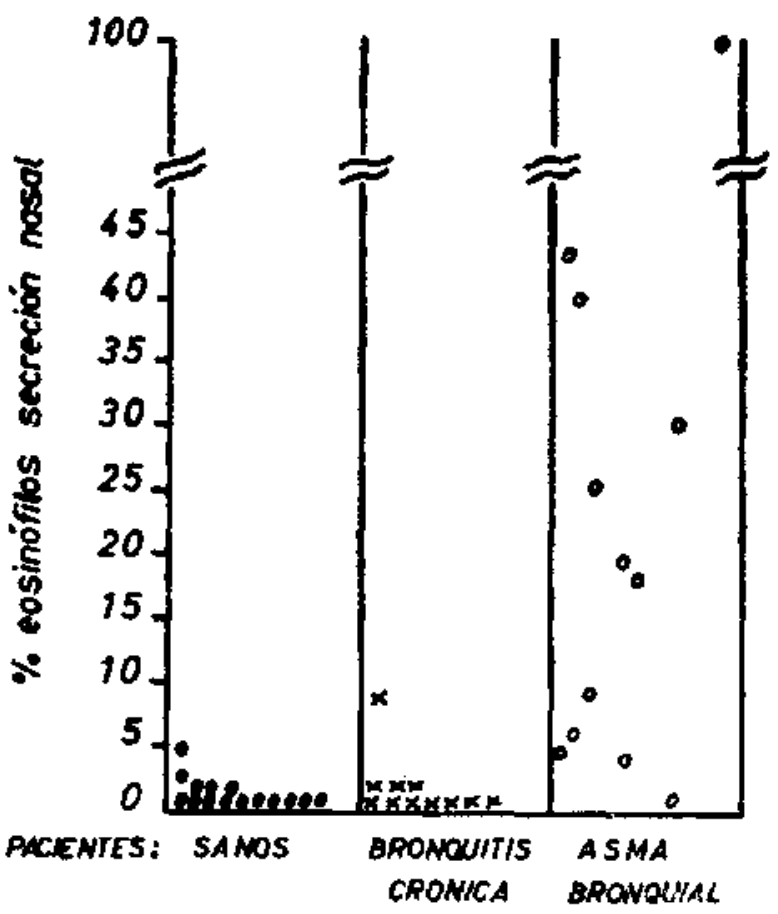

Fig. W? L. Eosinofilia cn la sccreción nasial de rin̄os sanos sin antecedentes alergicos, en pacientes con bronquitis crónica alérgica $y$ en enfermos con asma bronquial comprobada.

rencias observadas en el presente trabajo entrc niños con alergia demostrada y los no alérgicos indicarían su utilidad en el diagnóstico diferencial de los sindromes bronquiales obstructivos.

Es interesante destacar que en ocasiones la eosinofilia en secreción nasal puede aparecer previamente a alergias respiratorias que aún no se han manifestado. Crawford (12) observó que el $85 \%$ de los lactantes eccetnatosos de 3 o más meses de edad que tenían eosinofilias significativas en la secreción nasal presentaron posteriormente cuadros alérgicos respiratorios en contraste con el $37 \%$ de incidencia de alergia respiratoria en lactantes eccematosos sin eosinofilia nasal. Este autor hace notar que antes de los 3 meses de edad es posible encontrar una eosinofilia inespecifica normal que no debe inducir a errores de isterpretación.

Se ha demostrado que el número de eosinófilos en secreción nasal no se modifica en forma importante con tratamiento con antihistamínicos.

\section{RESUMEN}

1.- Se estudia el número de eosinófilos en la secrecion nasal de tres grupos de pacientes: ninos asmáticos, niños con sindrome bronquial obstructivo no alérgica y un grupo control de niños sanos.

2.- Se describe la técnica usada. método de Hansel.
3.-Los resultados permiten concluir que el recuento de eosinófilos en secreción nasal es un método facil y que puede ser de uilidad para el diagnóstico diferencial de cuadros bronquiales alérgicos y no atérgicos.

\section{SUMMARY}

1.- The eosinophiles Count in the nasal secretions is studied in the groups of children: asthmatics, non allergic obstructive bronchitis and a healthy control group.

2.-The Hansel method, wich was used, is described.

3. - The results lead is to conclude that the eosinophiles count in nawal secretions is an casy to practice method and that it might be helpful in the diferential diagnosis allergic and non allergic conditions of the bronchi.

\section{REFERENCIAS}

1.- Cerati E. Asma bronquial. En Meneghello J. Pediatría. Pág. 63. Intermédica, Buenos Aires, 1972.

2.-Dees S. Asthma. En Kendig E. Disorders of the Respiratory Tract in Children. W. B. Sauders $C O$. Púg. 449.

3. Tuft L., Mueller $I I$. Allergy in Children. W. B. Saunders, Pbiladelphia, 1970.

4.-Rhyne $M$. Pruebas cutáneas: conceptos y realidades. Clínicas Pediátricas de N. A., Febreru, 1969, pág. 227.

5.-Mansmonn $H$. Tratamiento del niño con asma bronquial. Clínicas pediátricas de N. A. Mayo, 1968, pág. 357.

6.-Eyermann C. Nasal manifestations of allergy. Ann. Otolaryng Rhin and Laryng 32: 808, 1927. Citado por Murray y Anderson, The J, of Allergy, 43: I, 1969.

7.-Murray $A$. and Anderson $D$. The epidemiological relationship of clinical nasal allergy to eosinophils and to goblet cells in the nasal smears. The $\mathrm{J}$, of Allergy, 43, 1, 1969.

8,- Lecks H. and Kravis L. Alergia y eosinofilos. Clínicas Pediátricás de N. A. Febrero, 1969, pág. 125.

9.-Epstein $R$. Sputum Eosinophilia in Obstructive Lung Disease. Annals of Internal Medicine. 75: $317,1972$.

10.-Fernández H. Ceruti E., Cassar C. y Diaz. A. Estudio del niño asmático mediante inducción de broncoconstricción con inhalación de acetil colina y polvo de habitación. Presentado en las III Jomidas de Pediatría, Punta Arenas, 1971. En prensa Rev. Chilesa de Pediatría.

11.-Sheldom \%.. Lowreell R., and Mathews E. A Minual of Clinical Allergy. Pág. 72, W. B. Saunders Co., Philadelphia, 1967.

12.-Crawford L. Ann Allergy, 18: 19, 1960. 